\title{
Formation of Intermetallic Phases in Ion Implantation
}

\author{
Fuzhang Wang $\mathbb{D},{ }^{1,2,3}$ Asfandyar Khan, ${ }^{4}$ Muhammad Ayaz, ${ }^{4}$ Imtiaz Ahmad $\mathbb{D},{ }^{5}$ \\ Rashid Nawaz, ${ }^{4}$ and Nisar $\mathrm{Gul}^{4}$ \\ ${ }^{1}$ School of Mathematical and Statistics, Xuzhou University of Technology, Xuzhou 2221018, Jiangsu, China \\ ${ }^{2}$ Nanchang Institute of Technology, Nanchang 330044, China \\ ${ }^{3}$ College of Mathematics, Huaibei Normal University, Huaibei 235000, China \\ ${ }^{4}$ Department of Mathematics, Abdul Wali Khan University, Mardan 23200, Pakistan \\ ${ }^{5}$ Department of Mathematics, University of Swabi, Khyber Pakhtunkhwa 23340, Pakistan \\ Correspondence should be addressed to Imtiaz Ahmad; imtiazkakakhil@gmail.com
}

Received 16 September 2020; Revised 11 October 2020; Accepted 19 October 2020; Published 29 October 2020

Academic Editor: K.S. Nisar

Copyright (c) 2020 Fuzhang Wang et al. This is an open access article distributed under the Creative Commons Attribution License, which permits unrestricted use, distribution, and reproduction in any medium, provided the original work is properly cited.

\begin{abstract}
This paper presents a model for the formation of intermetallic phases in the modified nickel ions in the surface layer of aluminum. It is shown that the absorption of ions in the bulk of the qualitative difference between the models with and without the relaxation of the mass flux is reduced to a difference in the characteristic scales. It was shown that the concentration distribution depends on the relation between time scales of various physical processes. We have extended the existing model to a unique simple model describing the formation of a new phase at the initial stage of ion implantation. The parameters containing in the model were evaluated using literature data. The known problem is a special case for our model.
\end{abstract}

\section{Introduction}

Intermetallics-chemical compounds of two or more metals-are widely used in modern science and technology, as they retain their structure and properties at high temperatures. The volume of intermetallic alloys is of great interest based on intermetallic compounds, which are applied in different ways. For example, a coating based on NiTi, obtained by laser ablation [1] significantly increases the wear resistance of the alloy $\mathrm{Ti}-6 \mathrm{Al}-4 \mathrm{~V}$. Coating the $\mathrm{Ti}-\mathrm{Cu}$ system significantly improves the surface properties of copper [2]. Intermetallic $\mathrm{Al}-\mathrm{Cu}$ system as coating deposition using CVD method [3] increases the corrosion resistance of steels and other compounds. Improved surface properties due to the formation of intermetallic phases, including intermetallic nanostructures, were possibly due to the implantation of metal ions in the surface layers of other metals. Reports of studies in this area have appeared for a long time [4]. These authors reported the formation of different phases in surface layer of steels and alloy layers depending on the conditions of implantation and subsequent annealing temperature. Formation of multilayer nanostructures in the $\mathrm{Al}-\mathrm{Ti}$ ion implantation of $\mathrm{Ar}^{+}$[5] is also accompanied by the formation of intermetallic compounds. The authors of $[6,7]$ have undertaken targeted research of formation of intermetallic phases in the surface layers, leading to changes in the mechanical properties, depending on the mode of implantation. These papers argue that the formation of chemical compounds is an important modification component of surface properties. The first model of the process of ion implantation with the chemical steps was proposed in [8], where the phase sequence obtained surface layer, similar to the experiments [6]. However, the nonequilibrium nature of the evolution of the surface layer that is associated with the nonequilibrium mass transfer in these studies was not considered. Wave processes were at the initial stage of the study of ion implantation, for example, in $[9,10]$. A simplified model of the process with a single chemical reaction in the surface layer, but considering the finite relaxation time of the mass flow, is proposed in $[11,12]$. 
In this paper, continuing research, we take a model for nonequilibrium conditions of three-stage reaction for the formation of intermetallic compounds.

\section{Statement of the Problem}

We consider a model for nonequilibrium conditions of three-stage reaction for the formation of intermetallic compounds. Consider the flat nickel layer. The flow of aluminum particles is distributed uniformly along the surface to be treated. Suppose that the implantation of aluminum ions into the nickel surface may occur as follows:
(a) $\mathrm{Ni}+\mathrm{Al} \longrightarrow \mathrm{NiAl}$
(b) $3 \mathrm{Ni}+\mathrm{Al} \longrightarrow \mathrm{Ni}_{3} \mathrm{Al}$
(c) $\mathrm{Ni}_{3} \mathrm{Al}+2 \mathrm{Al} \longrightarrow 3 \mathrm{NiAl}$

The molar concentration distribution of $\mathrm{Ni}, \mathrm{Al}, \mathrm{NiAl}$, and $\mathrm{Ni}_{3} \mathrm{Al}$ follows from equations. For simplicity, we assume that $Y_{1}=[\mathrm{Al}] ; Y_{2}=[\mathrm{Ni}] ; Y_{3}=[\mathrm{NiAl}]$; and $Y_{4}=\left[\mathrm{Ni}_{3} \mathrm{Al}\right]$, and the reaction rate can be written in accordance with the law of mass action

$$
\begin{aligned}
& \phi_{1}=k_{1} Y_{1} Y_{2}, \\
& \phi_{2}=k_{2} Y_{1} Y_{2}^{3}, \\
& \phi_{3}=k_{3} Y_{1}^{2} Y_{4}
\end{aligned}
$$

Then, the concentration will vary in accordance with the following equation:

$$
\begin{aligned}
\frac{\partial Y_{1}}{\partial t} & =-\frac{\partial J_{1}}{\partial x}+\omega_{1}+q_{m} F(x, t), \\
\frac{\partial Y_{2}}{\partial t} & =-\frac{\partial J_{2}}{\partial x}+\omega_{2}, \\
\frac{\mathrm{d} Y_{3}}{\mathrm{~d} t} & =\omega_{3}, \\
\frac{\mathrm{d} Y_{4}}{\mathrm{~d} t} & =\omega_{4},
\end{aligned}
$$

where $F(x, t)=F_{1}(x) F_{2}(t), q_{m}$ denotes maximum flux density of particles, and

$$
\omega_{k}=\sum_{i=1}^{r} v_{k i} \phi_{i}, \quad r=3 ; i=1,2,3 ; k=1,2,3,4 .
$$

Particle flows $\left(\mathrm{mol} /\left(\mathrm{m}^{2} \mathrm{~s}\right)\right)$ satisfy the generalized law

$$
\begin{aligned}
& J_{1}=-D_{1} \frac{\partial Y_{1}}{\partial x}-t_{1} \frac{\partial J_{1}}{\partial t} \\
& J_{2}=-D_{2} \frac{\partial Y_{2}}{\partial x}-t_{2} \frac{\partial J_{2}}{\partial t},
\end{aligned}
$$

where $D_{1}$ and $D_{2}$ are diffusion coefficients and $t_{1}$ and $t_{2}$ are the relaxation times.

The boundary conditions are as follows:

$$
J_{1}=J_{2}=0, x=0 \text {, and } x=L .
$$

At the initial time,

$$
\begin{aligned}
& Y_{1}=Y_{3}=Y_{4}=0, \\
& Y_{2}=Y_{20} .
\end{aligned}
$$

Numerically, we use double-sweep method and implicitdifference scheme. The computations are concentration distributions of elements and phases at various times while varying the model parameters.

\section{Results Analysis}

For illustrations taken,

$$
F(x, t)=\exp \left(-A x^{2}\right) H\left(t-t_{\mathrm{imp}}\right),
$$

where $H\left(t-t_{\text {imp }}\right)$ is a unit step function; $t_{\text {imp }}$ is the pulse duration; and $A=50^{-2} \mathrm{~cm}^{-2}$. Diffusion coefficients and reaction rates depend on temperature by Arrhenius law. The activation energy of reactions is taken from [13] (Table 1).

The diffusion coefficients are the same, as in $[11,12]$.

If $t_{1}=t_{2}=0$, this model is useful for slow process, when the reaction rate is controlled by slow diffusion. The preexponential factor can adapt with ideal conditions for a chemical reaction when there is no kinetic troubles as shown in Table 1. The mass concentration can be determined utilizing the following formula:

$$
C_{k}=\frac{Y_{k} m_{k}}{\sum_{i=1}^{4} Y_{i} m_{i}}
$$

where $m_{k}$ denotes molar masses of substances. From Figure 1 it is clear that, at a temperature $T=600 \mathrm{~K}$ phase, $\mathrm{Ni}_{3} \mathrm{Al}$ is practically not formed. Appearing as an intermediate, it is quickly spent on the formation of phase NiAl. Practically, the diffusion at this temperature is absent. An injected item is consumed where it has been injected. After exhausting Al, in this area, the reaction is almost stopped. At a temperature $T=800 \mathrm{~K}$, the ratio between the reaction rate changes. As a result, there is a region where we have a finite portion or part of the phase of $\mathrm{Ni}_{3} \mathrm{Al}$.

With increasing temperature to $T=1000 \mathrm{~K}$, the diffusion zone is activated. Evidently, in the treating zone, the phase is preferably NiAl. This can be followed by a zone containing predominantly phase $\mathrm{Ni}_{3} \mathrm{Al}$. Zone sizes depend on the temperature of the mass flux density, which is in qualitative agreement with the data $[6,7]$.

Model for $t_{1} \neq 0$ and $t_{2} \neq 0$ is of interest for treating conditions of short pulses with a high particle density. To ensure that the observed reaction under these conditions, it is necessary to take into account the possible acceleration of the reactions and diffusion, for example, by activation [14]. Qualitatively different effects in a model taking into account the relaxation compared to the traditional version of the model are not found. For example, when $t_{1}=1 \cdot 10^{-4}$ and $t_{2}=1 \cdot 10^{-3}$ at the initial stage of the processing flow particle density (see equation for the first component) $q_{m}=1.5 \cdot 10^{5}\left(\mathrm{~mol} / \mu \mathrm{m}^{3} \mathrm{~s}\right)$, the chemical reaction is observed, if the speed increases from $\left(10^{4} \div 10^{8}\right)$.

Figure 2 shows a steady slow increase in the occupied phase area $\mathrm{NiAl}$ and a mixture of the two phases 
TABLE 1: Formal-kinetic parameters of reactions.

\begin{tabular}{lccc}
\hline- & $\mathrm{Ni}+\mathrm{Al} \longrightarrow \mathrm{NiAl}$ & $3 \mathrm{Ni}+\mathrm{Al} \longrightarrow \mathrm{Ni}_{3} \mathrm{Al}$ & $\mathrm{Ni}_{3} \mathrm{Al}+2 \mathrm{Al} \longrightarrow 3 \mathrm{NiAl}$ \\
\hline$E_{a},{\mathrm{~J} . \mathrm{mol}^{-1}}$ & 86128.77 & 169148.544 & 148715.212 \\
$k_{0}$ & $8.994 * 10^{4}$ & $1.517 * 10^{9}$ & $0.853 * 10^{2}$ \\
\hline
\end{tabular}
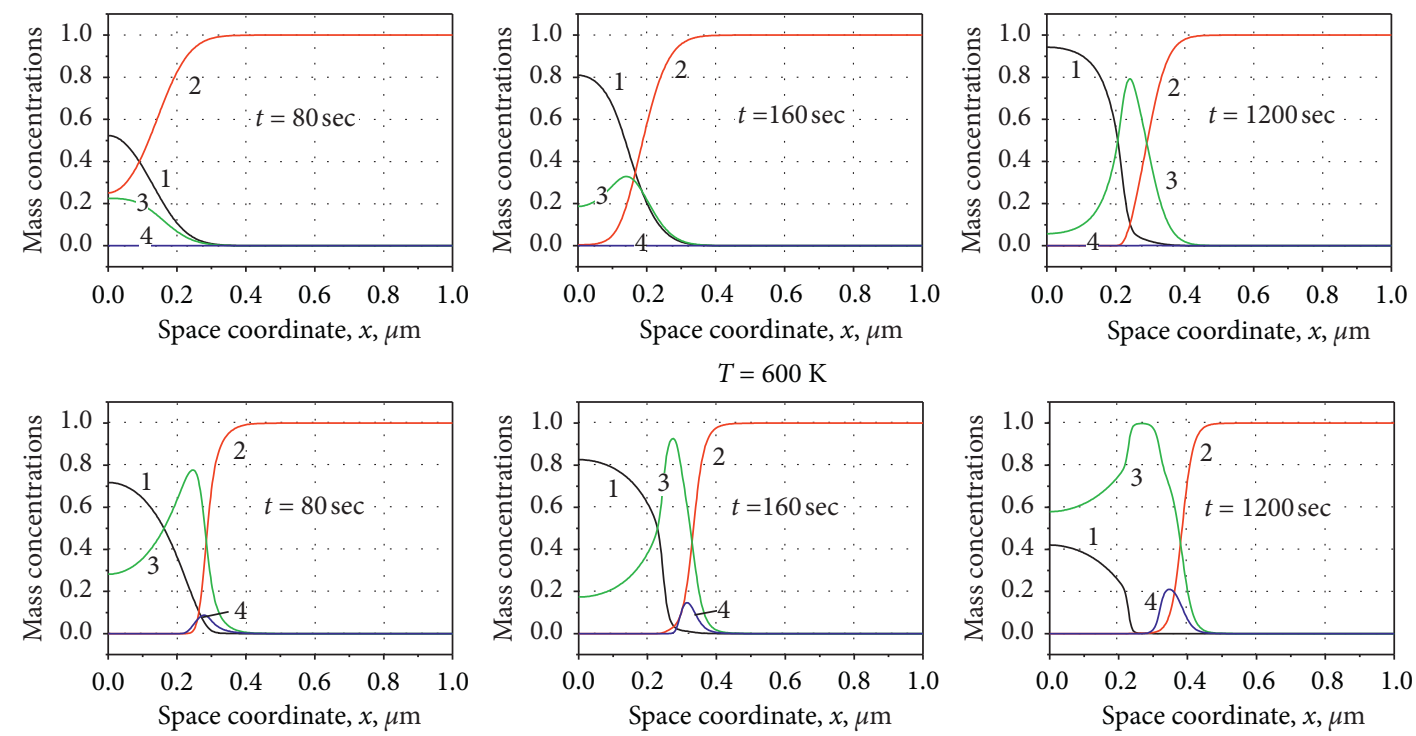

$T=800 \mathrm{~K}$
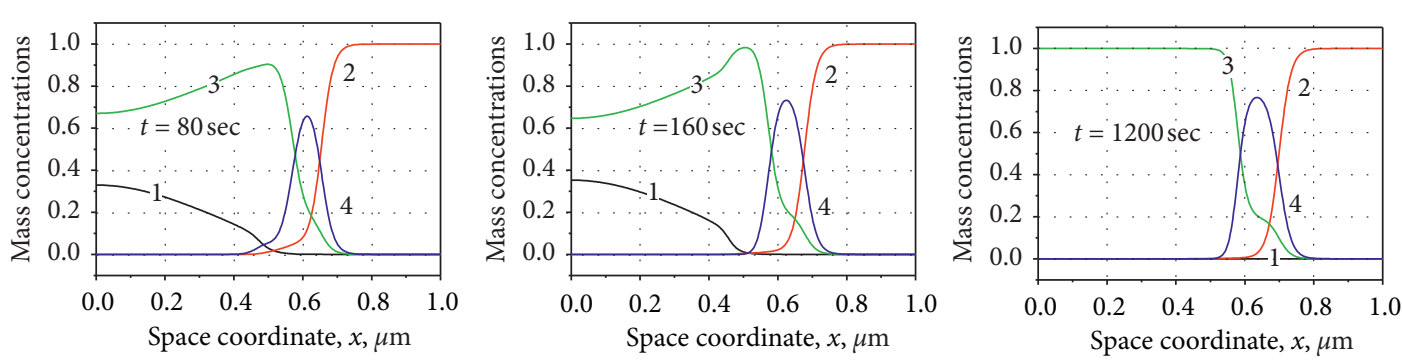

$T=1000 \mathrm{~K}$

Figure 1: The distribution of phases and elements at various times and at various temperatures are given for the slow process, $q_{m}=0.3\left(\mathrm{~mol} / \mu \mathrm{m}^{3} \mathrm{~s}\right) ; t_{\mathrm{imp}}=400 \mathrm{sec}$.
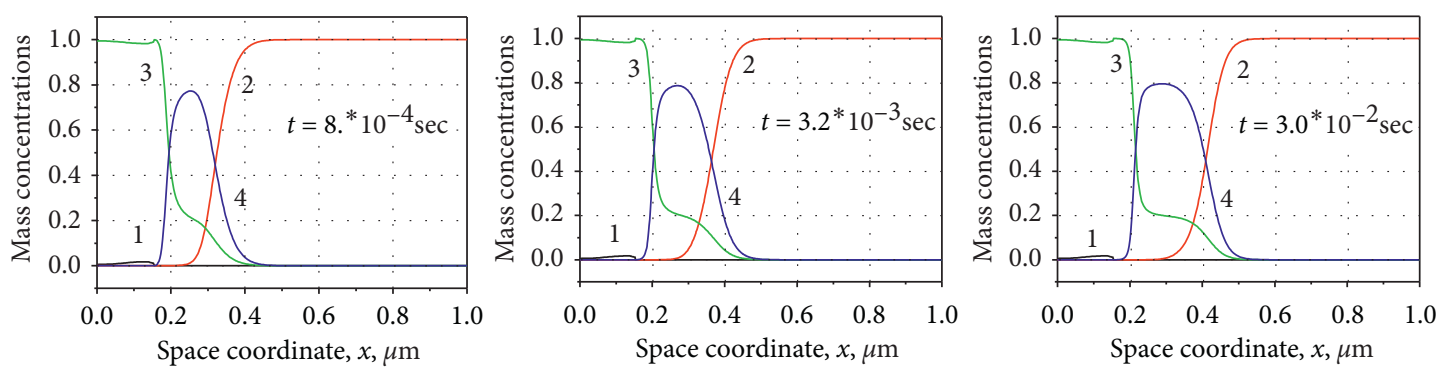

FIgURE 2: Distribution of phases and elements at various times at a temperature $T=1000 \mathrm{~K}$ for a "fast" process: a steady stream. 
$\mathrm{NiAl}+\mathrm{Ni}_{3} \mathrm{Al}$. This feature is only for a richer separation of the two zones.

\section{Novelty of the Work [15]}

The paper, for the first time, formulated and investigated related models on thermal elastic diffusion with chemical reactions. The algorithms were developed excluding the possibility of inconsistency appearance in terms of physical solutions. Based on the results of numerical modeling, the new effects were revealed. The work presents a new knowledge in the thermal elastic diffusion theory with chemical reactions. Results of the study can be used to develop models and methods of composition modification with acceptable treated samples. Models admit their further development by taking into account the different parameters and conditions of ion deposition.

\section{Conclusion}

Thus, in this paper, a model has been constructed in order to describe the intermetallic formation on surface layers during ion implantation, with the assumption of isothermal condition. The implicit-difference scheme has been suggested for the solution of diffusion kinetic problem describing ion implantation by intermetallic phase formation. For further interesting models and methods, we refer the readers to [16-32]. We actually suggest a model of the surface modification of nickel-aluminum ions with the relaxation of mass flows. The model corresponds to irreversible conditions and includes finiteness of relaxation times for mass fluxes. The results illustrate the convergence of difference schemes at variation of its parameters. It has also been shown that the finiteness of relaxation time changes the concentration distribution in the diffusion zone in comparison with usual diffusion problems with high temperature.

\section{Data Availability}

The data used to support the findings of this study are available from the corresponding author upon request.

\section{Conflicts of Interest}

The authors declare that they have no conflicts of interest.

\section{Acknowledgments}

This work was partially supported by the Anhui Provincial Natural Science Foundation (project no. 1908085QA09) and Natural Science Research Project of Anhui Province (project no. KJ2019A0591).

\section{References}

[1] M. MokgadyNomsa, P. SisaLesleyPityana, P. Abimbola Idowu, and T. Mathebula, "NiTi intermetallic surface coatings by laser metal deposition forInproving wear properties of $\mathrm{Ti}-$ $6 \mathrm{Al}-4 \mathrm{~V}$ substrate," Advances in Materials Science and Engineering, vol. 2014, Article ID 363917, 2014.
[2] M. Salehi and R. Hosseini, "Structural characterisation of novel Ti-Cu intermetallic coatings," Surface Engineering, vol. 12, no. 3, pp. 221-224, 1996.

[3] LyacineAloui, T. Duguet, F. Haidara et al., "Al-Cu intermetallic coatings processed by sequential metalorganic chemical vapour deposition and post-deposition annealing," Open Archive Toulouse Archive Ouverte (OATAO), vol. 258, no. 17, pp. 6425-6430, 2012.

[4] H. Dionisiop, B. A. S. De Barros, and I. J. R. Baurnvol, "Intermetallic phases formed during tin implantation into iron and steels," Journal of Applied Physics, vol. 55, no. 12, pp. 4219-4224, 1984.

[5] D. Perusko, S. Petrovic, M. Stojanovic et al., "Formation of intermetallics by ion implantation of multilatered $\mathrm{Al} / \mathrm{Ti}$," Nuclear Instruments and Methods in Physics Research B, vol. 282, pp. 4-7, 2012.

[6] I. A. Kurzina, E. V. Kozlov, Y. P. Sharkeev et al., "Influence of ion implantation on nanoscale intermetallic-phase formation in Ti-Al, Ni-Al and Ni-Ti systems," Surface and Coatings Technology, vol. 201, no. 19-20, pp. 8463-8468, 2007.

[7] I. A. Bozhko, S. V. Fortuna, I. A. Kurzina, I. B. Stepanov, E. V. Kozlov, and Y. P. Sharkeev, "Formation of nanoscale intermetallic phases in $\mathrm{Ni}$ surface layer at high intensity implantation of $\mathrm{Al}$ ions," Journal of Materials Science and Technology, vol. 29, no. 5, pp. 583-586, 2004.

[8] A. G. Knyazeva, J. P. SharkeevKurzina, and I. A. Bozhko, "Modeling the interaction of high-intensity beams of ions of aluminum with a nickel target," in Proceedings of the VI International Conference "Interaction of Radiation with Solids, pp. 125-128, Minsk, Belarus, September 2005.

[9] E. S., V. N. D. Ilina and A. G. Knyazev, "Details of modeling of diffusion processes in an elastic body under its surface modification of particles," Bulletin PNIPU, Mechanics, Publishing House of Perm GTU, vol. 3, pp. 26-50, 2012.

[10] E. S. Parfenova, A. G. Knyazeva, and Y. P. Azhel, "Dynamics of diffusion and mechanical waves interaction under conditions of metal surface treatment with particle fluxes," Advanced Materials Research, vol. 1040, p. 466, 2014.

[11] A. Khan and A. G. Knyazeva, "Surface layer composition change under irreversible conditions of particle beam action," Advanced Materials in Research, vol. 1040, pp. 596-601, 2014.

[12] A. Khan and G. Anna, "Knyazeva new phase synthesis in surface layer in the conditions of ion implantation," Applied Mechanics and Materials, vol. 1623, pp. 245-249, 2014.

[13] I. A. Kurzina, V. KozlovE, and Y. P Sharkeev, Nanocrystalline Intermetallic and Nitride Structures, which are Formed in IonPlasma Exposure, NTL, Noida, India, 2008.

[14] A. G. Knyazev and S. G. Psakhie, "Thermodynamics activated state materials," Journal of Applied Mechanics and Technical Physics, vol. 50, pp. 118-126, 2009.

[15] A. Khan, Problems of Thermal Elastic Diffusion with Chemical Reactions, Tomsk Polytechnic University Russian Federation, Tomsk, Russia, 2017, http://earchive.tpu.ru/bitstream/11683/ 38239/1/vkr_Khan.pdf.

[16] N. A. Sheikh, D. L. C. Ching, I. Khan, D. Kumar, and K. S. Nisar, "A new model of fractional casson fluid based on generalized fick's and fourier's laws together with heat and mass transfer," Alexandria Engineering Journal, vol. 59, no. 5, pp. 2865-2876, 2020.

[17] N. A. Sheikh, M. Jamil, D. Ling Chuan Ching, I. Khan, M. Usman, and K. S. Nisar, "A generalized model for quantitative analysis of sediments loss: a caputo time fractional," Journal of King Saud University-Science, 2020. 
[18] N. A. Sheikh, F. Ali, M. Saqib et al., "Comparison and analysis of the atangana-baleanu and caputo-fabrizio fractional derivatives for generalized Casson fluid model with heat generation and chemical reaction," Results in Physics, vol. 7, pp. 789-800, 2017.

[19] I. Ahmad, H. Ahmad, A. E. Abouelregal, P. Thounthong, and M. Abdel-Aty, "Numerical study of integer-order hyperbolic telegraph model arising in physical and related sciences," The European Physical Journal Plus135, vol. 9, pp. 1-14, 2020.

[20] M. Inc, M. N. Khan, I. Ahmad, S. W. Yao, H. Ahmad, and P. Thounthong, "Analysing time-fractional exotic options via efficient local meshless method," Results in Physics, vol. 19, Article ID 103385, 2020.

[21] I. Ahmad, M. N. Khan, M. Inc, H. Ahmad, and K. S. Nisar, "Numerical simulation of simulate an anomalous solute transport model via local meshless method," Alexandria Engineering Journal, vol. 59, no. 4, pp. 2827-2838, 2020.

[22] H. Ahmad, T. A. Khan, P. S. Stanimirović, Y.-M. Chu, and I. Ahmad, "Modified variational iteration algorithm-ii: convergence and applications to diffusion," Complexity, vol. 2020, Article ID 8841718, , 2020.

[23] M. N. Khan, I. Hussain, I. Ahmad, and H. Ahmad, "A local meshless method for the numerical solution of space-dependent inverse heat problems," Mathematical Methods in the Applied Sciences, 2020.

[24] I. Ahmad, H. Ahmad, P. Thounthong, Y.-M. Chu, and C. Cesarano, "Solution of multi-term time-fractional PDE models arising in mathematical biology and physics by local meshless method," Symmetry, vol. 12, no. 7, p. 1195, 2020.

[25] H. Ahmad, A. Akgül, T. A. Khan, P. S. Stanimirović, and Y.-M. Chu, "New perspective on the conventional solutions of the nonlinear time-fractional partial differential equations," Complexity, vol. 2020, p. 1, 2020.

[26] A. Yokus, H. Durur, H. Ahmad, P. Thounthong, and Y.-F. Zhang, "Construction of exact traveling wave solutions of the bogoyavlenskii equation by $\left(\mathrm{G}^{\prime} / \mathrm{G}, 1 / \mathrm{G}\right)$-expansion and $\left(1 / G^{\prime}\right)$-expansion techniques," Results in Physics, vol. 19, Article ID 103409, 2020.

[27] A. Akgül and H. Ahmad, "Reproducing kernel method for fangzhu's oscillator for water collection from air," Mathematical Methods in the Applied Sciences, 2020.

[28] O. Bazighifan, H. Ahmad, and S.-W. Yao, "New oscillation criteria for advanced differential equations of fourth order," Mathematics, vol. 8, no. 5, p. 728, 2020.

[29] M. Nawaz, I. Ahmad, and H. Ahmad, "A radial basis function collocation method for space-dependent inverse heat problems," Journal of Applied and Computational Mechanics, vol. 6, no. SI, pp. 1187-1199, 2020.

[30] H. Ahmad, A. R. Seadawy, T. A. Khan, and P. Thounthong, "Analytic approximate solutions for some nonlinear parabolic dynamical wave equations," Journal of Taibah University for Science, vol. 14, no. 1, pp. 346-358, 2020.

[31] N. A. Shah, I. Ahmad, B. Omar, A. E. Abouelregal, and H. Ahmad, "Multistage optimal homotopy asymptotic method for the nonlinear riccati ordinary differential equation in nonlinear physics," Applied Mathematics \& Information Sciences, vol. 14, no. 6, pp. 1-7, 2020.

[32] M. Srivastava, H. Ahmad, I. Ahmad, P. Thounthong, and N. Khan, "Numerical simulation of three-dimensional fractional-order convection-diffusion PDEs by a local meshless method," Thermal Science 210 pages, 2020. 